\title{
Vibration isolation for parallel hydraulic hybrid vehicles
}

\author{
The M. Nguyen and Mohammad H. Elahinia* \\ Department of Mechanical, Industrial, and Manufacturing Engineering, Dynamic and Smart Systems Laboratory, \\ University of Toledo, $2801 \mathrm{~W}$ Bancroft, Toledo, OH 43606, USA
}

Received 12 July 2006

Revised 5 February 2007

\begin{abstract}
In recent decades, several types of hybrid vehicles have been developed in order to improve the fuel economy and to reduce the pollution. Hybrid electric vehicles (HEV) have shown a significant improvement in fuel efficiency for small and medium-sized passenger vehicles and SUVs. HEV has several limitations when applied to heavy vehicles; one is that larger vehicles demand more power, which requires significantly larger battery capacities. As an alternative solution, hydraulic hybrid technology has been found effective for heavy duty vehicle because of its high power density. The mechanical batteries used in hydraulic hybrid vehicles (HHV) can be charged and discharged remarkably faster than chemical batteries. This feature is essential for heavy vehicle hybridization. One of the main problems that should be solved for the successful commercialization of HHV is the excessive noise and vibration involving with the hydraulic systems. This study focuses on using magnetorheological (MR) technology to reduce the noise and vibration transmissibility from the hydraulic system to the vehicle body. In order to study the noise and vibration of HHV, a hydraulic hybrid subsystem in parallel design is analyzed. This research shows that the MR elements play an important role in reducing the transmitted noise and vibration to the vehicle body. Additionally, locations and orientations of the isolation system also affect the efficiency of the noise and vibration mitigation. In simulations, a skyhook control algorithm is used to achieve the highest possible effectiveness of the MR isolation system.
\end{abstract}

Keywords: Hydraulic hybrid vehicles, noise and vibration, transmissibility, magnetorheological fluids

\section{Introduction}

Hybrid vehicles combine more than one source of energy for propulsion to achieve higher fuel efficiency and lower pollution. The simplest example is the motorized pedal bike (moped) which utilizes a hybridization of electric motor and human muscles. Nuclear energy and electric sources are combined to provide propulsion for submarines. Recently, gasoline-electric passenger vehicles, or hybrid electric vehicles (HEV), have become popular. Various configurations exist for gasoline-electric hybrid vehicles, and the two main ones are series and parallel designs [16]. Despite the enhanced fuel economy and reduced pollution, a significant disadvantage of the gasoline-electric hybrid is due to its limited power capability [8]. Maximum power density of electric batteries is approximately $2 \mathrm{~kW} / \mathrm{kg}$. The specific power decreases dramatically at low temperatures. Therefore, it is only feasible to apply gasoline-electric hybridization to small and medium-sized vehicles. This is due to the fact that larger vehicles will require significantly larger battery capacities. Additionally, maintenance process of the batteries and electric motors is costly. Also, the batteries are made of scarce metals and most of them are very harmful to the environment $[9,20]$.

Hydraulic hybrid technology is developed as an alternative solution for heavy-duty vehicles. The main feature of hydraulic hybrid systems is their high power density [27]. Hydraulic accumulators can function as mechanical batteries, which are capable of quick recharge to or discharge from very high pressure without compromising their

\footnotetext{
*Corresponding author. Tel.: +1 419530 8224; Fax: +1 419530 8206; E-mail: mohammad.elahinia@utoledo.edu.
} 


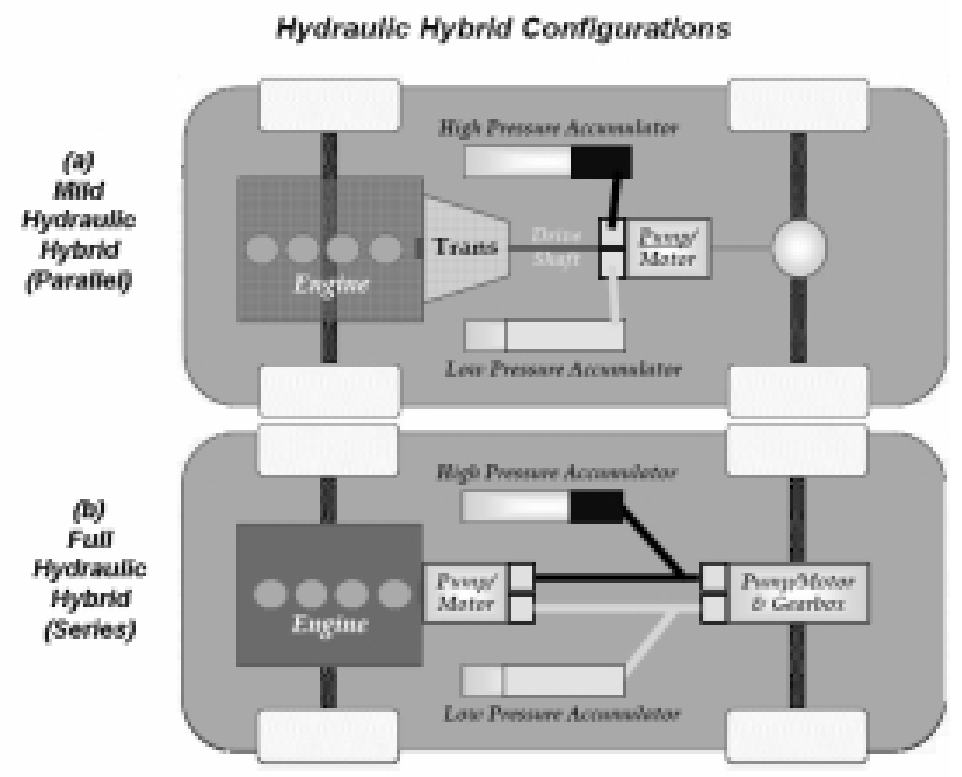

Fig. 1. Two main configurations of Hydraulic hybrid vehicles [27]: (a) parallel, (b) series.

efficiency. For example, at 5000 psi pressure, the power density of an accumulator is $3 \mathrm{~kW} / \mathrm{kg}$, and that of a hydraulic pump/motor unit is $5 \mathrm{~kW} / \mathrm{kg}[14,16,27]$. Hydraulic fluid has a wide range of working temperature from $-54{ }^{\circ} \mathrm{C}$ to $236^{\circ} \mathrm{C}$. This technology is also environmentally friendly since no toxic chemicals are used in any components. Regular transmission fluids are being used as hydraulic fluids, and they can be recycled after being used for hydraulic hybrid purposes. Therefore, hydraulic hybrid technology is suitable for heavy vehicles such as shuttle buses, refuse trucks, and delivery trucks where high power is needed to propel the vehicle and a large amount of energy is available for harvesting from braking.

The hydraulic hybrid main components are a dual function pump/motor (P/M), a low-pressured accumulator (LP-A) and a high-pressured accumulator (HP-A). Hydraulic hybrid vehicles, as shown in Fig. 1, exist in two configurations: parallel and series. In the parallel design, which is also called Hydraulic Launch Assist (HLA ${ }^{\circledR}$ ) by Eaton Corporation or Hydraulic Power Assist (HPA ${ }^{\circledR}$ ) by Ford Motor Company, the hydraulic subsystem (HSS) is integrated in parallel to the drivetrain of a regular vehicle. The main objective is to capture the large amount of the energy that is lost in frictional braking and to utilize that energy to propel the vehicle in its next acceleration. HSS can be seen as an add-on to the conventional powertrain without any fundamental changes of how the vehicle operates. When the brake is pressed, kinetic energy of the vehicle is captured by the P/M to charge hydraulic fluid from LP-A to HP-A. When the gas pedal is pressed, the process is reversed. The hydraulic flow from HP-A back to LP-A makes the P/M work as a motor to transform the hydraulic energy to rotational motion at the wheels. In this process, the engine only contributes to the vehicle propulsion when most of the stored hydraulic energy is used.

In the series design, as illustrated in Fig. 1, the conventional drivetrain is completely replaced by the fluid line connecting two P/M's. The main hydraulic components of this configuration are the same as the ones of parallel design. The engine only provides the input torque to operate the first $\mathrm{P} / \mathrm{M}$. The fluid power is transferred to the second $\mathrm{P} / \mathrm{M}$, which is integrated with the gearbox and located at the rear axel. The hydraulic energy is transformed into rotary motion by the second $\mathrm{P} / \mathrm{M}$. This second $\mathrm{P} / \mathrm{M}$ is also connected to the high and low pressured accumulators. The excess amount of fluid, during driving cycles, is pumped to the high pressured accumulator and stored there. The regenerative braking process in the series design is done similar to that in the parallel design. In a series HHV the engine can potentially operate at its optimal condition and/or be turned off leading to better fuel economy and less pollution. 


\subsection{Hydraulic hybrid vehicles}

Hydraulic hybrid technology is being studied at several universities and institutes in the US, Australia, Denmark, and Japan. Matheson and Stecki studied HHV models for heavy-duty vehicles such as trucks and buses [21]. They built a regenerative energy powertrain which is similar to the parallel design shown in Fig. 1. It was shown that the performance of HHV is comparable to conventional vehicles, while they have a better fuel efficiency. As part of this development, a hydraulic hybrid FMTV Army Tactical Vehicle was tested through a series of fuel trials and maximum acceleration test runs to measure the effectiveness of the hybridization.

Kepner proposed the use of a HHV model for smaller vehicles such as SUVs and light trucks [19]. With a 7000 $\mathrm{lb}$ vehicle and a 150cc pump/motor, analysis showed that it was possible to absorb $72 \%$ of the available braking energy in the EPA city cycle with the parallel HHV system. The calculation was done with the assumption of an ideal hydraulic subsystem with no energy loss during liquid flow and storage. The vehicle demonstrated even greater benefits driving a cycle with more aggressive acceleration and braking events. His study also suggests that HHV architecture may have significant practical potential for fuel economy and performance benefits in road vehicles.

More recently, the experimental results from the US Environmental Protection Agency (EPA) and its partners have proven the potential of HHV in on-road applications [14]. They introduced the first ever SUV, a Ford Expedition, with the full hydraulic hybrid drivetrain as shown in Fig. 1. It was shown that the fuel economy can be increased by as much as $80 \%$. That combines about $50 \%$ improvement in fuel efficiency due to hybridization and another $30-40 \%$ by switching from a gasoline to a diesel engine. Projected information of acceleration and deceleration time also indicates better performance than the conventional Expedition [27].

\subsection{Noise and vibration of $H H V s$}

As it is known, hybrid vehicles operate based on the combination of two or more power systems. Those power systems are alternating to provide propulsion for the vehicles. Therefore, each power system is at one of two states during its working cycles. The states are on (operating) and off (idling or shut-off). Besides, the vehicle's powertrain is experiencing the engagement and disengagement from those power systems when they are turned on or switched off. A significant amount of noise and vibration come from the switching states and the engagement/disengagement mechanism of the hybrid vehicles [30]. Kepner pointed out that one of the main problems with the hydraulic hybrid subsystem is the high level of noise and vibration [19]. This is partly because the system's operation is based on fluid flow at high velocity and high pressure. The peak pressure in the high-pressure accumulator can be as high as 5000 psi. During braking events, pumping noise is noticeable. The primary sources of noise are from the pump/motor pistons passing by the pump ports, and from hydraulic valve opening and closing events. Noise also can be generated by hydraulic fluid flow inside the tubing system. Prek investigated the noise problem of hydraulic systems generated by tubing geometry [23]. The research indicated that the geometrical parameters determine the levels and characteristics of noise emission. On the other hand, Johansson et al. suggests dealing with the hydraulic systems noise problem at its origins [18]. The noise and vibration created inside the pump/motor mainly have two different origins. First, the cylinder pressures acting on the pistons will create piston forces inside the P/M. Second, the pump generates flow ripple which will be transformed to pressure ripple and noise. By optimizing the pump geometry, the flow ripple can be reduced significantly for one specific condition, i.e. one specific pressure. However, the pressure acting on the pistons is changing. Edge presented a comprehensive review of different noise reducing design features for hydraulic systems [13]. The review indicates the importance of considering all noise sources created by hydraulic systems, especially the pump/motor unit. Thus, to minimize the overall noise emission for piston pumps/motors, flow ripple, piston forces and swash plate moments must be considered.

The study of noise and vibration problems with hydraulic systems has been limited to proposing potential solutions to keep the noise level as low as possible. Since the noise and vibration problems still affect the commercialization of the hydraulic hybrid technology, it is important to effectively isolate the hydraulic subsystem from the chassis in order to reduce the transmitted noise and vibration. 


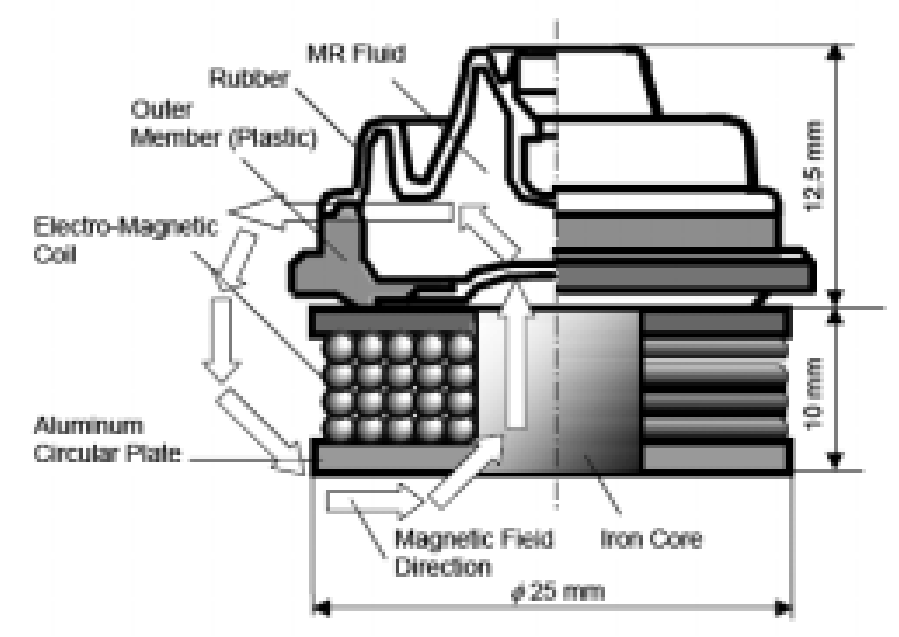

Fig. 2. Schematic view of a small size variable-damping mount using MR fluid [6].

\subsection{Vibration isolation}

A major challenge in designing mounts is to make them sufficiently stiff so that they can hold the two structures together, yet make them dynamically soft so that they can provide isolation [5]. Engine rubber (elastomeric) mounts are effective means for reducing noise and vibration and have been studied extensively. Akanda and Adulla applied evolutionary computation for tuning powertrain mounts [7]. This tuning solution in order to provide maximum isolation, instead of reducing the mount stiffness, decouples the vibration rigid-body modes of the powertrain through the torque-roll-axis method. This idea behind the decoupling is that if a system is completely decoupled in physical modes, excitation along one physical coordinate only excites one mode. The dynamic stiffness of the elastomeric mounts increases with the frequency. This property is one of the main limitations of the rubber mounts.

Hydraulic (fluid) mounts overcome some of the drawbacks of the elastomeric mount. It is possible to design a fluid mount that has a significantly larger static stiffness, compared to an elastomeric mount, with much smaller dynamic stiffness at a specific frequency (notch frequency) that can be tuned to the primary frequency of the vibration source. These mounts, at the notch frequency provide the best isolation (notch depth). The isolation performance of the mounts, however, deteriorates at the resonance frequency. It is desirable that the transmissibility peak at the resonance frequency is as small as possible and the notch depth is as close to zero as possible.

In some applications passive engine mounts are not sufficient. As an example, Honda has recently developed an active mount as part of a cylinder-on-demand engine technology [17,22]. This mount mitigates the vibration caused by torque fluctuation when the six-cylinder engine operates with three cylinders to achieve better fuel economy. A hydraulic mount is combined with a solenoid linear actuator, which is controlled in a feed-forward manner. The controller based on the engine pulses estimates the phase and level of the vibration and adjust the duty signal of the actuator inside each active mount.

Semi-active mounts are attractive vibration isolators because they have advantages from both passive and active mounts. Magnetorheological (MR) fluids can be used to realize semi-active vibration isolators [10]. These controllable fluids are made of micron size iron particles that are suspended in a carrier fluid. MR fluids respond to an applied magnetic field with a change in their rheological behavior. Ahn et al. presented the idea of using MR fluids to enhance the performance of a fluid vibration mount [2-4]. In this concept, the MR fluid was used in the valve mode. Using simulations, it was shown that the concept MR fluid mount provides isolation over a wider range of frequencies.

Ahn and his colleagues developed and experimentally investigated a small MR mount (shown in Fig. 2) for precision automotive applications to replace the currently used mounts that are filled with high viscosity silicone oil [6]. Stelzer et al. showed that a MR semi-active isolator, which works in the flow mode, can reduce noise and vibration transmissibility in automobiles [26]. Different vibration inputs were considered including shock, vibration 


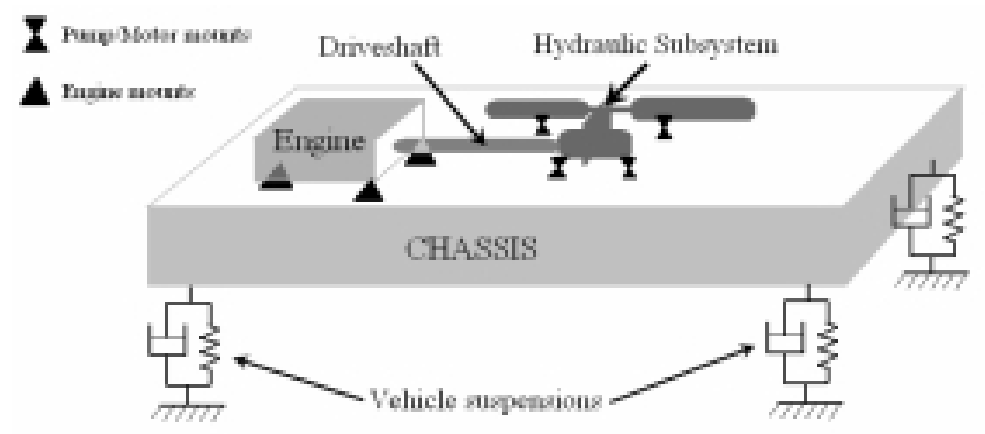

Fig. 3. Full-vehicle model of a parallel HHV.

with single or range of frequency. MR force was controlled by turning the magnetic field on and off by a skyhook controller. Ye and Williams utilized MR fluid brake in torsional vibration control in rotating systems [29]. In their study, the MR fluid brake was model as passive and semiactive friction damper. Their experimental results indicated that in both models, the torsional vibration amplitude was significantly reduced. However, the semiactive controlled model did achieve better performance than the passive constant current model.

In this paper, an isolation system combined from passive element (elastomer) and semi-active element (MR) is studied through simulations in order to minimize the noise and vibration transmissibility from the hydraulic subsystem (HSS) to the vehicle body. To this end, a dynamical model is developed in MATLAB/Simulink. This model represents the realistic motion of the system in six directions including three translational ones along $\mathrm{x}$, $\mathrm{y}, \mathrm{z}$ axes and three rotational ones about these axes. A skyhook controller was designed to achieve the optimal performance of the MR mount.

\section{Modeling}

In order to study the vibration characteristics of hydraulic hybrid vehicles, a model is developed in Simulink using the SimMechanics toolbox. The model consists of three rigid bodies namely the vehicle chassis, the hydraulic subsystem (HSS), and the engine. Each body has its own mass, center of gravity (CG) and moments of inertia. The chassis is connected to the ground through four suspension systems which include passive spring and damper, i.e. constant stiffness and damping coefficient. The HSS is connected to the chassis through four MR fluid mounts. The engine is also connected to the chassis through three MR fluid mounts. Thus, the HSS and the engine mounts are capable of varying their damping characteristics. Besides, a very stiff spring is used to represent the metal drive-shaft connecting the engine and the HSS. Each body is capable of moving in three translational and three rotational directions. Figure 3 shows the full-vehicle model of the parallel hydraulic hybrid vehicle.

Physical parameters of the bodies in this model are based on the specifications of heavy duty vehicles such as Ford F-350. Vibration excitation is modeled by using an external force constantly acting on the hydraulic subsystem. In the simulation model, this excitation force is represented by the chirp signal that sweeps through a range of frequency with specified amplitude. In a hydraulic hybrid vehicle, the hydraulic subsystem is engaged to the shaft when the RPM of the engine is between 0 and 2000 resulting in vibration excitation in the range of 0 to $300 \mathrm{~Hz}$.

\section{Control of isolation system}

Different control algorithms have been investigated for magnetorheological systems. Introduced by Crosby and Karnopp, the skyhook control has been adapted and modified to work with a large number of vibration isolation applications [12]. As shown in Fig. 4, the damper is attached to a fixed fictional reference in the sky. With the skyhook control, compared to the performance of the passive isolation system, a better vibration isolation from the base to the 

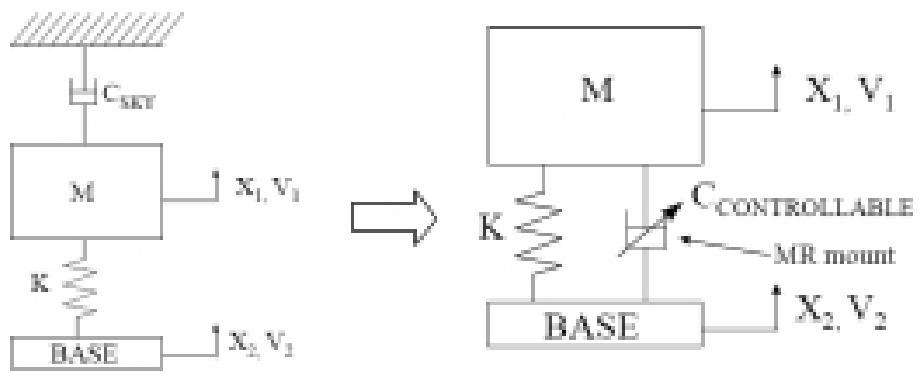

Fig. 4. Ideal Skyhook configuration is adapted for a semiactive suspension [24].

mass is achieved. Reichert used this skyhook controller for MR dampers used in vehicle seat suspensions [24]. To control the MR damper on or off state, Ahmadian developed the control method based on fuzzy logic for skyhook and groundhook algorithms [1]. A simplified model of vehicle roll-plane (half-car) was constructed for the application of the controller. The simulation results showed a substantial improvement in reducing the rollover likelihood in heavy trucks due to vehicle maneuvers. However, the study showed that the semiactive suspension could cause larger body acceleration peaks, and harsher ride.

Choi et al. proposed a cylindrical MR damper for passenger car suspension [11]. They used flow-mode damper in full vehicle model. H infinity controller was introduced to cope with the uncertainties of the system. For the bump excitation, the controller showed significantly improved results in vibration isolation. For random vibration excitation, the effectiveness of the suspension was also remarkable.

The controller used in this study is based on skyhook algorithm. The MR mounts can be set at one of two states ON or OFF. The mount is OFF when no current is provided to it. In this case, the mount has lowest value of passive damping. When current is constantly supplied to the mount, it is in ON state and has the highest value of passive damping. During the operational schedule, the controller determines which states the mount is at by turning on/off the current in order to achieve the best vibration isolation. The controller of the engine mounts depends on the product of the velocities of the engine and the chassis. Similarly, the controller of the HSS mounts uses the product of the velocities of the HSS and the chassis as reference values. The control algorithm is explained in the following two conditions.

The P/M mounts are controlled as:

$$
\left\{\begin{array}{l}
\text { ON if } V_{\text {chassis }} \cdot V_{\text {HSS }}<0 \\
\text { OFF if } V_{\text {chassis }} \cdot V_{\text {HSS }}>0
\end{array}\right.
$$

Similarly, the engine mounts are controlled as:

$$
\left\{\begin{array}{l}
\mathrm{ON} \text { if } \mathrm{V}_{\text {chassis }} \cdot \mathrm{V}_{\text {Engine }}<0 \\
\text { OFF if } \mathrm{V}_{\text {chassis }} \cdot \mathrm{V}_{\text {Engine }}>0
\end{array}\right.
$$

\section{Simulation results}

In this section, the results of vibration isolation simulation is presented. In the simulations, the hydraulic Pump/Motor is excited with a chirp signal with the frequency range of 0 to $300 \mathrm{~Hz}$. The goal of the research is to find the solution for the NVH problem associated with the HHV, which is caused by the operation of the hydraulic subsystem (HSS). To this end, motion of the chassis, the Pump/Motor (i.e. HSS) and the engine is recorded to investigate the efficiency of the MR mount in reducing the vibration transmissibility. In order to ensure the comfort for the passengers, the isolation of the chassis from the vibrating HSS and engine is very important.

In presenting the result graphs, there are four plots displaying the vibration response under four cases of damping configurations at the mounts. These cases represent different combination of passive and semi-active mounts. Figures 5, 6 and 7 respectively present the position of the HSS, the engine, and the chassis under different damping conditions at the mounts. 


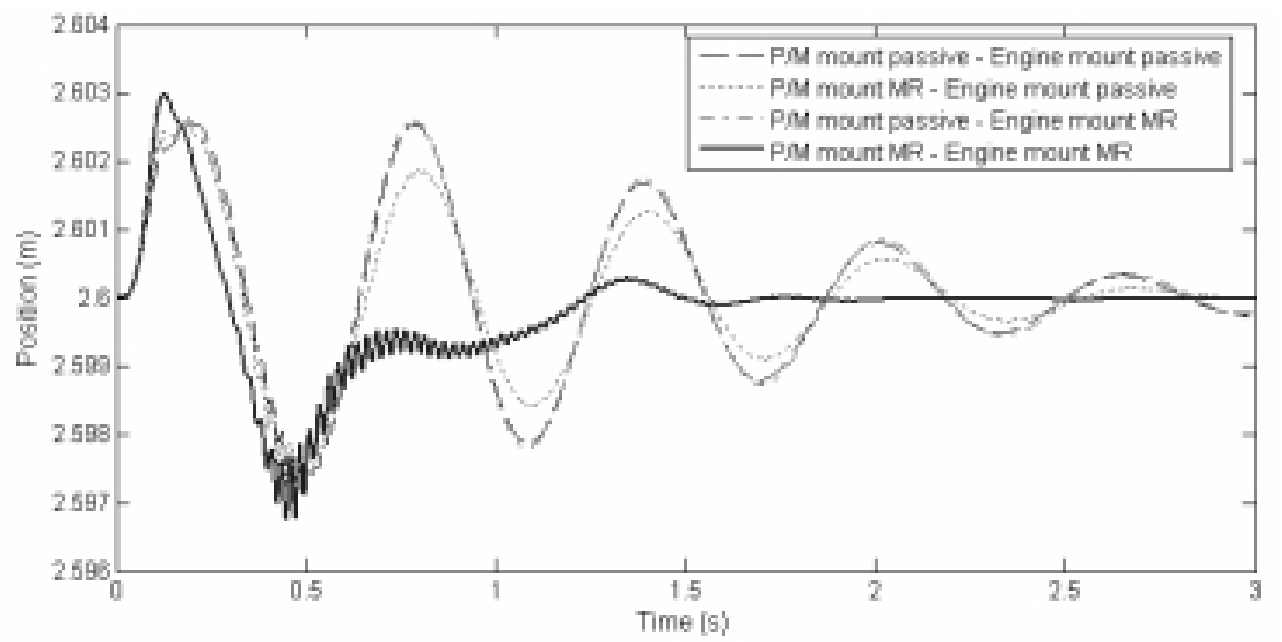

Fig. 5. Position of the hydraulic subsystem (HSS) in time domain.

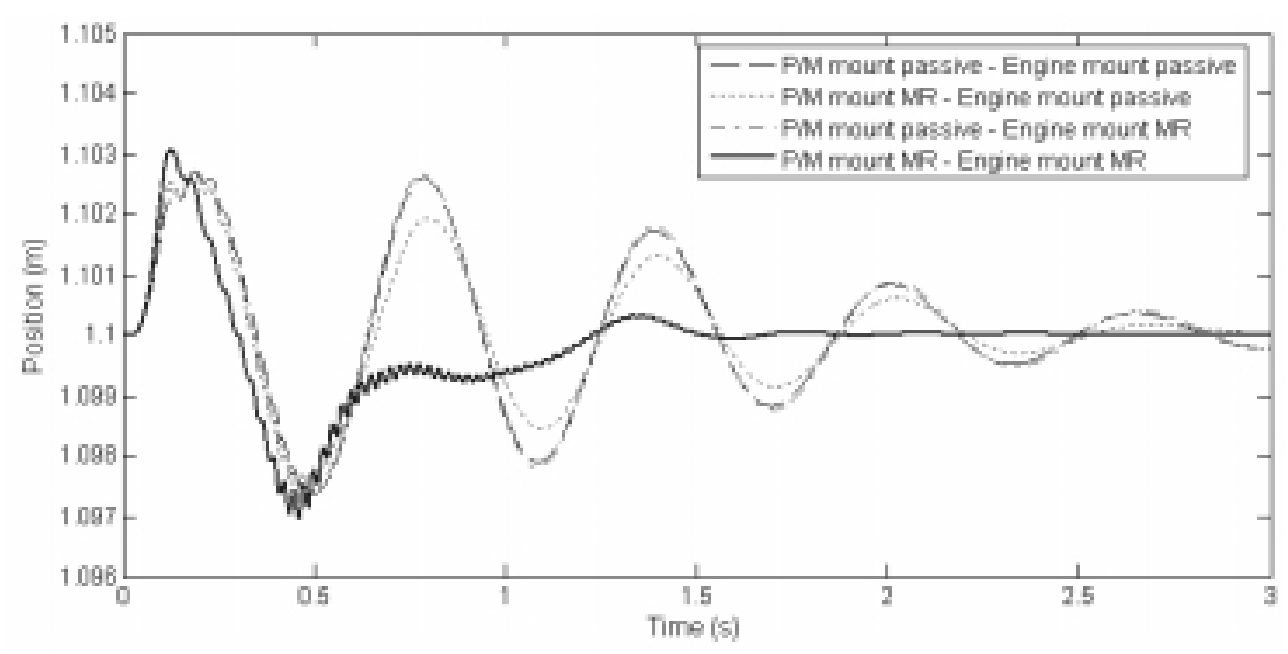

Fig. 6. Position of the engine in time domain.

It can be seen that the configuration with MR mounts at the engine and passive mounts at the $\mathrm{P} / \mathrm{M}$ does not significantly reduce the displacement amplitude. When the MR mounts are used at the P/M mounts along with passive mounts at the engine, the displacement amplitude is slightly reduced. The vibration, on the other hand, is much reduced when MR mounts with skyhook controller is used at both the P/M and the engine. It is noticeable that with this configuration the settling time is also significantly shorter. After the first period of oscillation, the displacement is quickly reduced and stabilized after one more period.

Figures 5, 6 and 7 also show the difference between the time responses of the chassis with that of the HSS and the engine. The transition from oscillation motion to the steady state at the $\mathrm{P} / \mathrm{M}$ and the engine is trembling while that at the chassis is smooth. This phenomenon is due to the fact that when the MR semiactive is in effect, the mounts provide a large amount of damping forces acting on the bodies. With much smaller masses compared to the chassis's, the HSS and the engine exhibit the resisting force induced vibration. However, this vibration is brief and small enough not to affect the P/M and the engine performance. The force provided by the mount and the acceleration of the body are plotted in time domain in Figs 8 and 9. The response variation between 0.4 and 1.3 seconds correlates well with the unsmooth transition in the P/M's and engine's displacement shown in Figs 5 and 6. Figures 8, 9 also 


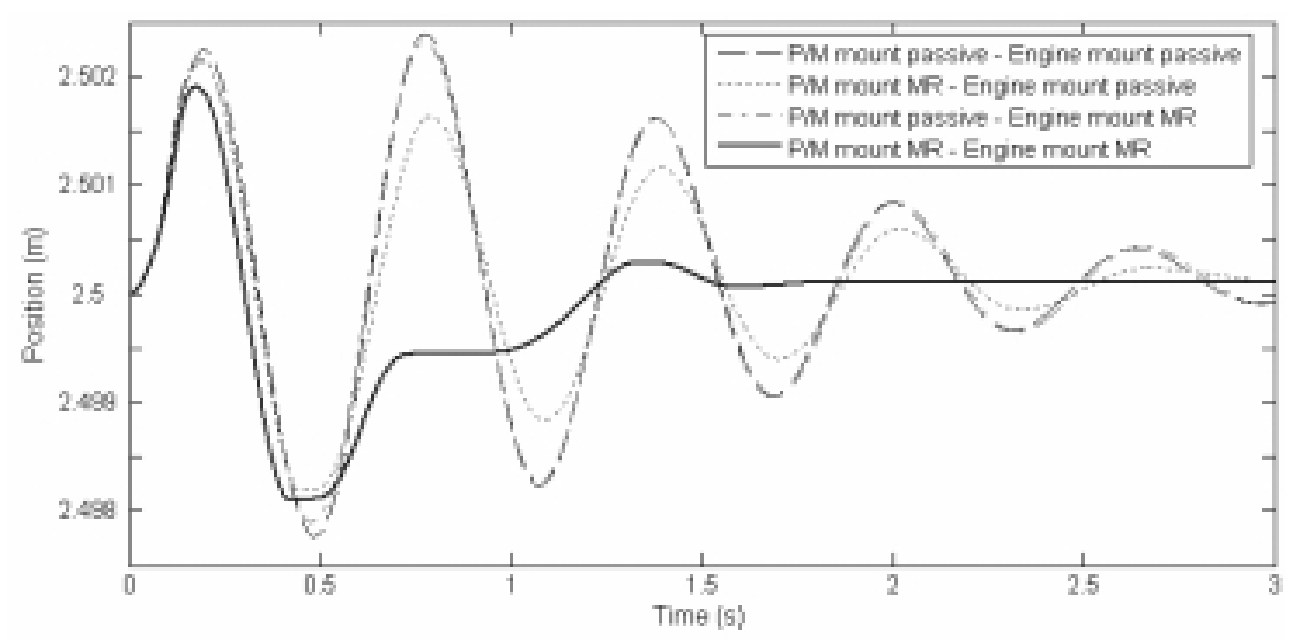

Fig. 7. Position of the chassis in time domain.

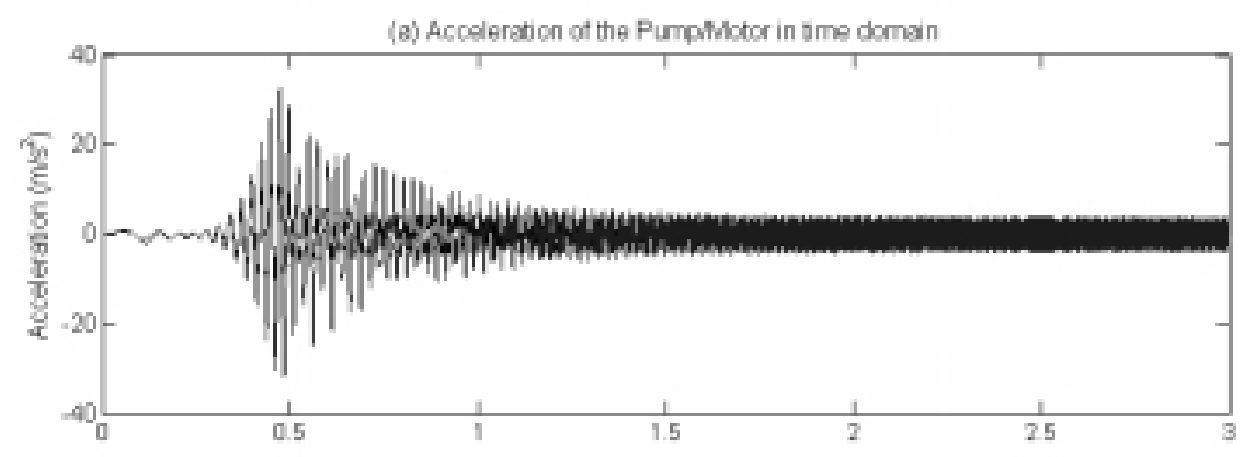

(b) Total force provided by the Purnplinotor mourts in time domain

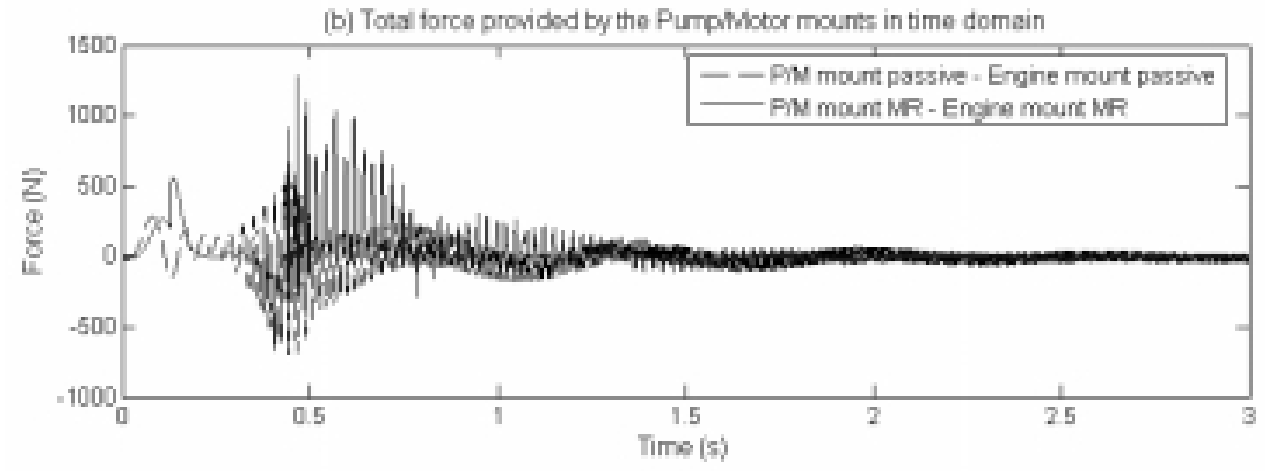

Fig. 8. Acceleration of the P/M in time domain (a) and force provided by the P/M mounts in time domain (b).

indicates that the MR mount with skyhook controller is capable of providing high enough damping force that can reduce the body's vibration quickly.

In this study, beside the motion in time domain, force transmissibility through the mounts in frequency domain is investigated as a criterion to assess the performance of the mounting configurations. When MR mounts are used at the $\mathrm{P} / \mathrm{M}$ along with passive mounts at the engine, the force transmission through the P/M mounts remarkably drops as shown in Fig. 10. In this configuration, however, the transmitted force through the engine mounts to the chassis 

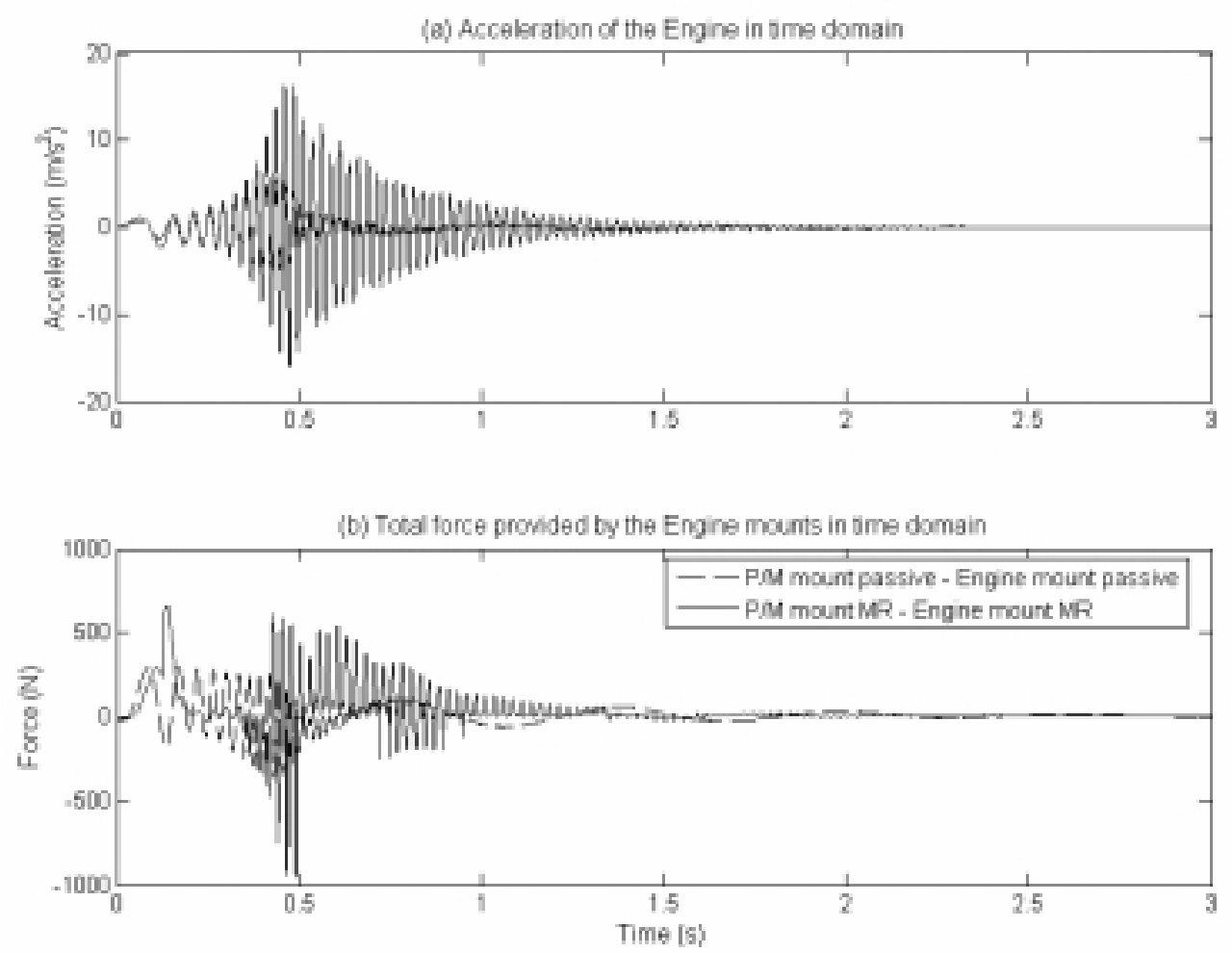

Fig. 9. Acceleration of the engine in time domain (a) and force provided by the engine mounts in time domain (b).

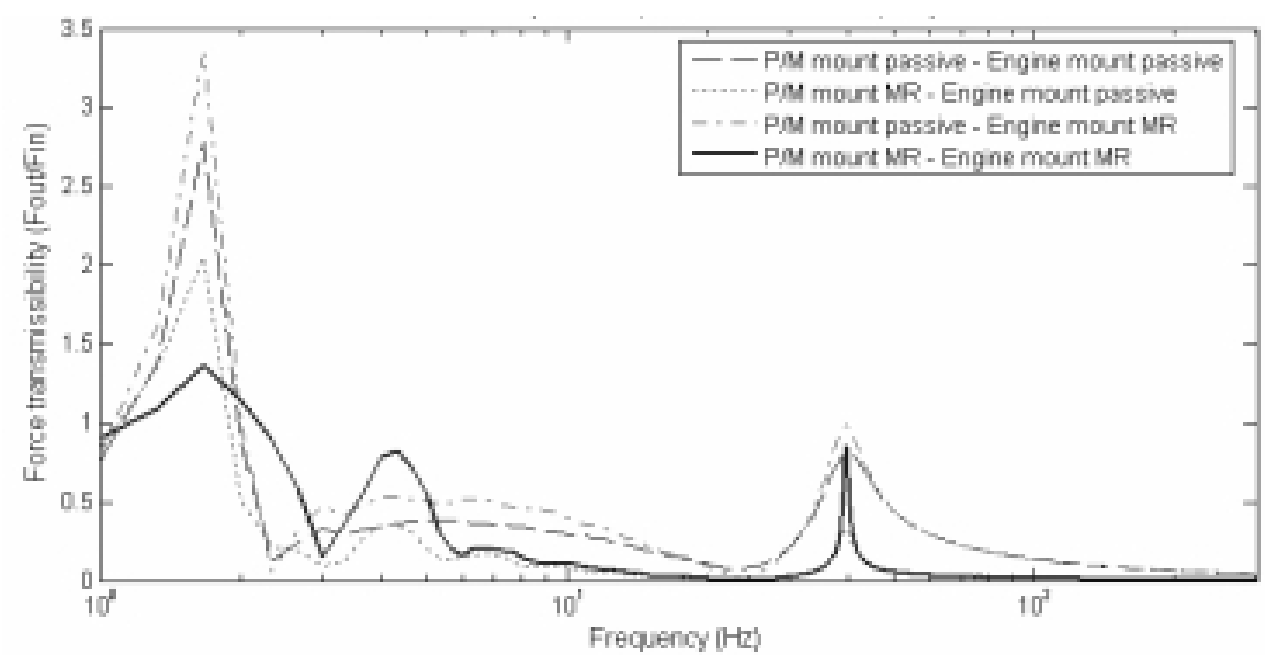

Fig. 10. Force transmissibility through the hydraulic subsystem (HSS) mounts to the chassis.

is extremely high, especially at the last peak of the curve as seen in Fig. 11. If MR mounts are used at the engine and the P/M mounts remain passive, Fig. 11 indicates that the isolation from the engine mounts is improved while Fig. 10 displays an opposite result for the force transmitted through the P/M mounts. Comparing to the performance of all passive mounts, the curve for all semiactive mounts has a significantly lower the first peak, little higher second peak and the same magnitude third peak. The force transmissibility curve of the all semiactive mounts is desired because it maintains low amplitudes throughout the whole range of operational frequency of the system. In this 


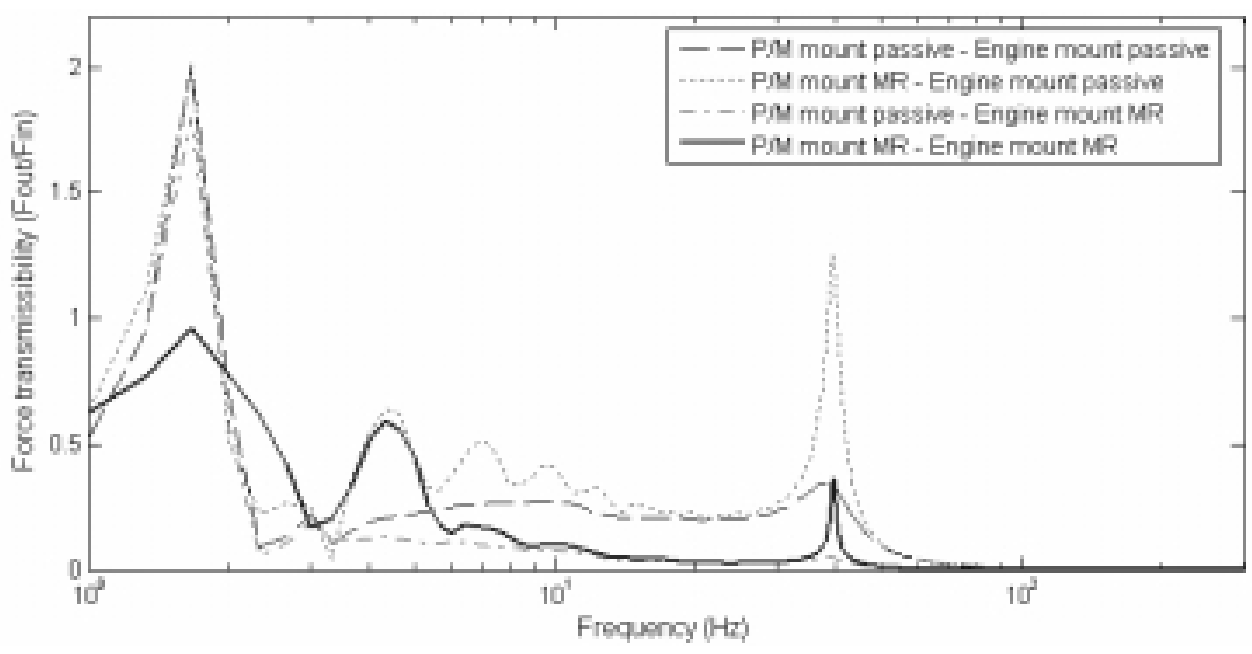

Fig. 11. Force transmissibility through the engine mounts to the chassis.

configuration, that the low force transmissibility occurs at both $\mathrm{P} / \mathrm{M}$ and engine mounts proves the best compromise in vibration isolation from the hydraulic subsystem and the engine to the chassis.

\section{Conclusions}

In this research, the nature of vibration problem involving with hydraulic hybrid vehicles was studied. A three body simulation model which consists of the chassis, the engine, and hydraulic subsystem (HSS) was constructed to show the behaviors of the system and the responses from the mounts. The HSS was excited with a chirp signal whose frequency ranges from 0 to $300 \mathrm{~Hz}$. Vibration was transmitted to the chassis through the P/M mounts and the engine mounts. The P/M mounts and the engine mounts use magnetorheological fluids so that they are capable of varying their damping characteristics. In this research, the mounts could be at either passive or semiactive with adopted skyhook control. The adopted skyhook control can turn ON/OFF the MR effect in the mounts according to the algorithm based on the velocities of the two connected bodies. The results showed that the semiactive MR mounts with skyhook control should be used for both the HSS and the engine in order to effectively isolate the vibration from the chassis. The semiactive mounts quickly reduced the vibration and maintained the motion at low amplitude for all bodies. When using MR semiactive mounts at both the P/M and the engine, the transition from oscillation to steady state in the motion of the HSS and the engine was not smooth. However, the roughness is insignificant to the HSS and the engine performance. The simulation results also indicated the effectiveness of the semiactive MR mounts in both time domain and frequency domain.

\section{Acknowledgements}

The authors would like to thank for the financial support and technical information from the US ARMY. The help is highly appreciated.

\section{Nomenclature}

3-D three dimensional

C damping coefficient

cc cubic centimeter(s) 
C.G. center of gravity

dir. direction

DOF degree of freedom

EPA environmental protection agency

F vibration excitation force

FEA finite element analysis

g gravitational acceleration

HEV hybrid electric vehicles

HHV hydraulic hybrid vehicles

HLA hydraulic launch assist

HPA hydraulic power assist

HP-A high-pressured accumulator

HHS hydraulic subsystem

$\mathrm{Hz}$ hertz

IC internal combustion

in inch(es)

$\mathrm{k} \quad$ stiffness

kg kilogram(s)

$\mathrm{kW} \quad$ kilowatt(s)

lb pound(s)

LP-A low-pressured accumulator

$\mathrm{m} / \mathrm{s}^{\wedge} 2$ meters per second squared

mpg miles per gallon

mph miles per hour

MR magnetorheological

NV noise and vibration

$\mathrm{NVH}$ noise, vibration and harshness

$\mathrm{P} / \mathrm{M}$ pump/motor

psi pounds per square inch

rev revolution(s)

RPM revolutions per minute

s seconds

SAE society of automotive engineers

SUV sport utility vehicles

\section{References}

[1] M. Ahmadian, On the development of fuzzy skyhook control for semiactive magnetorheological systems, Proceedings of SPIE Vol. 5760 (SPIE, Bellingham, WA 2005), 2005.

[2] M. Ahmadian and Y. Ahn, Performance analysis of magneto-rheological mounts, Journal of Intelligent Material Systems and Structures (10) (1999), 248-256.

[3] Y. Ahn, M. Ahmadian and S. Morishita, On the design and development of a Magneto-Rheological Mount, Proceedings of the 4th International on advanced vehicle control, 1998, 255-260.

[4] Y. Ahn, M. Ahmadian and S. Morishita, On the design and development of a Magneto-Rheological Mount, Vehicle System Dynamics (32) (1999), 199-216.

[5] Y. Ahn, Y. Kim, B. Yang, M. Ahmadian, K. Ahn and S. Morishita, Optimal design of an engine mount using an enhanced genetic algorithm with simplex method, Vehicle System Dynamics 43(1) (2005), 57-81.

[6] Y. Ahn, B. Yang, M. Ahmadian and S. Morishita, A Small-sized Variable-damping Mount using Magnetorheological Fluid, Journal of Intelligent Material Systems and Structures 16(2) (2005), 127-133.

[7] A. Akanda and C. Adulla, Application of evolutionary computation in automotive powertrain mount tuning, Shock and Vibration 13(2) (2006), 85-102.

[8] M. Anderman, Review - The challenge to fulfill electrical power requirements of advanced vehicles, Journal of Power Sources (2004).

[9] B.A. Anderson and I. Rade, Metal resource constraints for electric-vehicle batteries, Transportation Research Part D (6) (2001), $297-324$. 
[10] D. Carlson, D. Catanzarite and K. St. Clair, Commercial Magneto-Rheological Fluid Devices, Proceedings of the 5th International Conference on ER fluids, Magneto-rheological fluids and Related Phenomenon, 1995.

[11] Choi, Lee and Park, H $\infty$ Control Performance of a Full-Vehicle Suspension Featuring Magnetorheological Dampers, Vehicle System Dynamics 38(5) (2002), 341-360.

[12] M.J. Crosby and D. Karnopp, Vibration Control Using Semiactive Force Generator, Transactions of the ASME, Paper 73-DET-122, 1973.

[13] E.A. Edge, Designing quieter hydraulic systems - some recent developments and contributions, Fourth JHPS International Symposium, 1999.

[14] Fact sheet, 2004: "World First Full Hydraulic Hybrid SUV". 2004 SAE World Congress.

[15] P. Fontaine, Modeling Hydraulic Pump/Motors to Determine Force Components Leading to Noise, The Master of Science in Mechanical Engineering Thesis, Mechanical, Industrial and Manufacturing Engineering Department, College of Engineering, University of Toledo.

[16] R. Graham, Comparing the Benefits and Impacts of Hybrid Electric Vehicle Options, Electric Power Research Institute Report, 2001.

[17] T. Inoue, A. Takahashi, H. Sano, M. Onishi and Y. Nakamura, NV Countermeasure Technology for a Cylinder-On-Demand Engine Development of Active Booming Noise Control System Applying Adaptive Notch Filter, Proceedings of the SAE World Congress, 2004.

[18] A. Johansson, J.O. Palmberg and K.E. Rydberg, Cross angle - A Design Feature for Reducing Noise and Vibration in Hydrostatic Piston Pumps, Tenth International Conference of Fluid Power, 2002 [18].

[19] R.P. Kepner, Hydraulic Power Assist - A Demonstration of Hydraulic Hybrid Vehicle Regenerative Braking in a Road Vehicle Application, SAE Technical Paper Series - International Truck and Bus Meeting and Exhibition, 2002.

[20] L.B. Lave, A.G. Russell, C.T. Hendrickson and F.C. McMichael, Battery-powered vehicles: Ozone reduction versus lead discharges, Environmental Science and Technology 30(9) (1996), 402-407.

[21] Matheson and Stecki, Development and Simulation of Hydraulic-Hybrid Powertrain for Use in Commercial Heavy Vehicles, SAE Technical Paper Series - International Truck and Bus Meeting and Exhibition, 2003.

[22] H. Matsuoka, T. Mikasa and H. Nemoto, NV Countermeasure Technology for a Cylinder-On-Demand Engine Development of Active Control Engine Mount, Proceedings of the SAE World Congress, 2004.

[23] M. Prek, The impact of geometrical parameters on hydrodynamic noise generations, Applied Acoustic 60 (2000), $343-351$.

[24] B.A. Reichert, Jr., Application of magnetorheological dampers for vehicle seat suspensions, Master's Thesis. Mechanical Engineering, Virginia Polytechnic Institute and State University, 1997.

[25] Shimoyama, Ikeo, Koyabu, Ichiryu and Lee, Study on Hybrid Vehicle Using Constant Pressure Hydraulic System with Flywheel for Energy Storage, SAE Technical Paper Series - Powertrain \& Fluid Systems Conference and Expo, 2004.

[26] Stelzer, Schulz, Kim and Allemang, A Magnetorheological Semi-active Isolator to Reduce Noise and Vibration Transmissibility in Automobiles, Journal of Intelligent Material Systems and Structures 14 (2003), 743-765.

[27] United States Environmental Protection Agency (EPA), Progress Report on Clean and Efficient Automotive Technology under Development at EPA - Interim Technical Report, Office of Transportation and Air Quality, 2004.

[28] Wang and Liao, Modeling and Control of MR fluid dampers using neural networks, Smart Materials and Structures 14 (2004), 111-126.

[29] Ye and Williams, Torsional Vibration Control with an MR Brake, Proceedings of SPIE 5760, (SPIE, Bellingham, WA 2005), 2005.

[30] T. Yoshioka and H. Sugita, Noise and Vibration Reduction Technology in Hybrid Vehicle Development, SAE 2001-01-1415, 2001. 

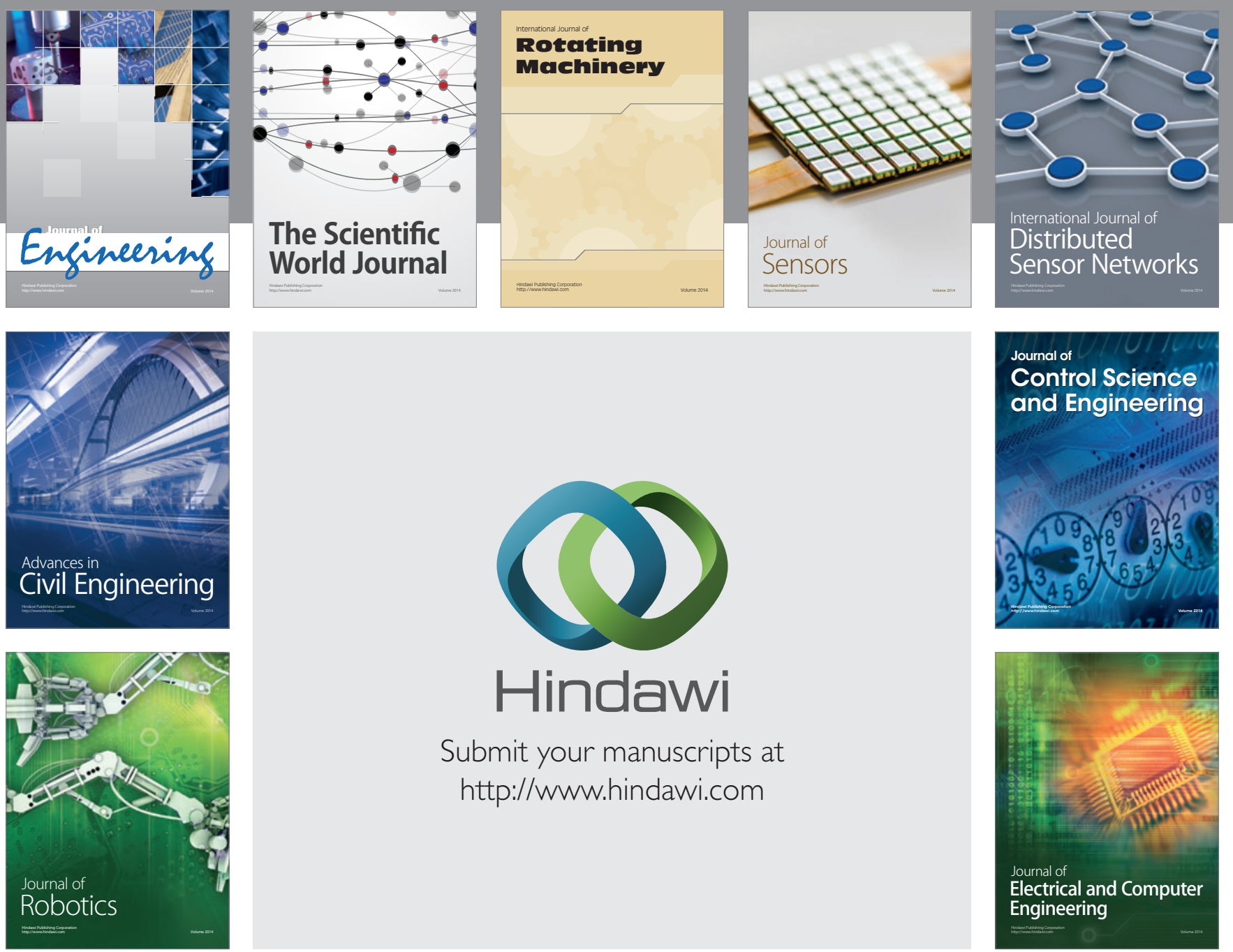

Submit your manuscripts at

http://www.hindawi.com
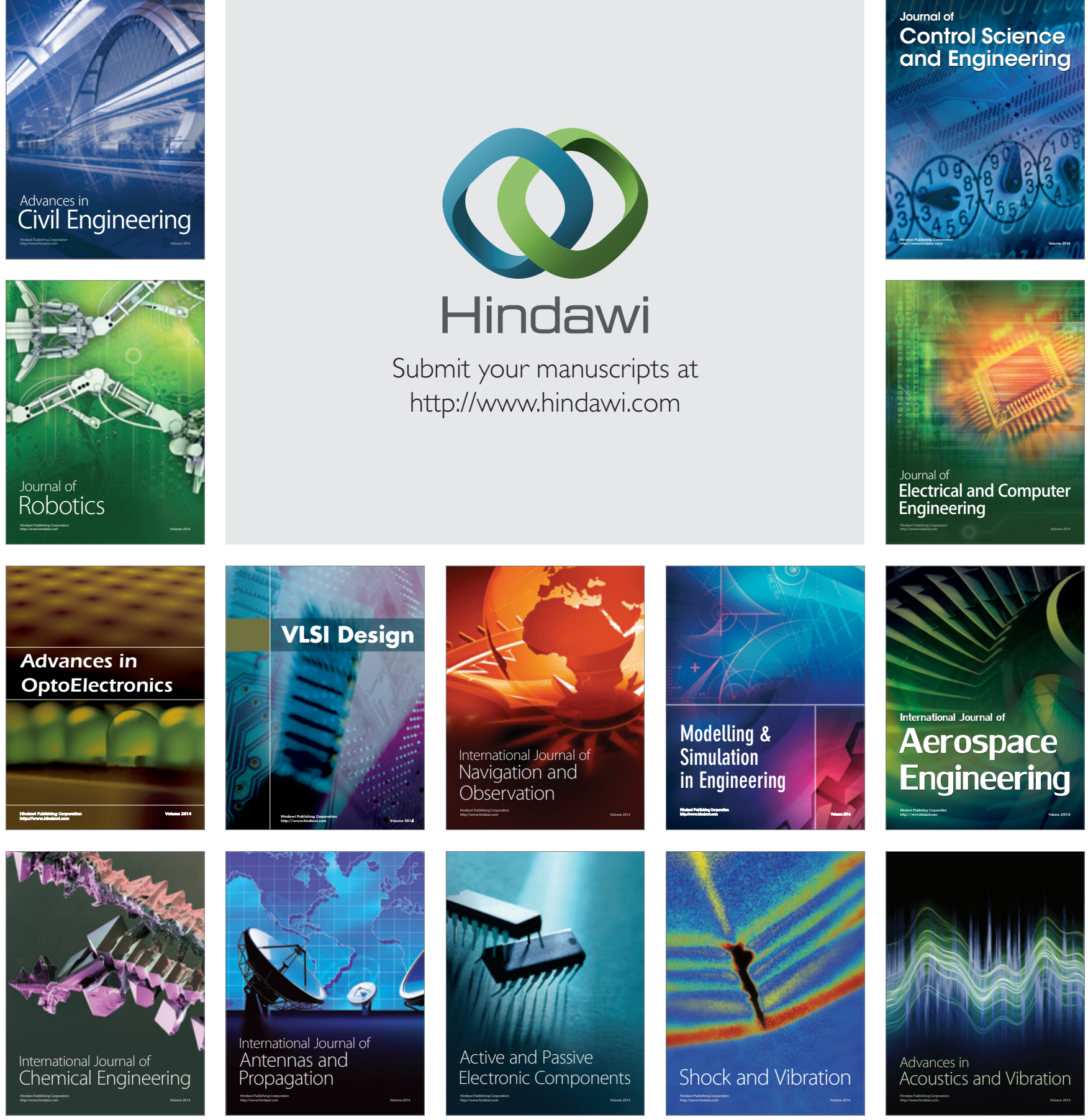